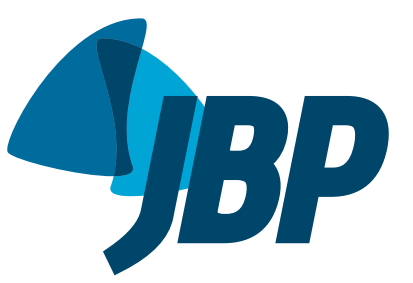

\section{A mobile calcified nodule in the pleural cavity: thoracolithiasis}

\author{
Dante Luiz Escuissato ${ }^{1, a}$, Gláucia Zanetti²,b, Edson Marchiori ${ }^{2, c}$
}

A 50-year-old female smoker was referred to our hospital for evaluation of a pulmonary nodule seen on a chest $X$-ray during a routine check-up. She was asymptomatic from a respiratory point of view. The physical examination findings and laboratory test results were unremarkable. Chest CT demonstrated the presence of a calcified nodule in the left pleural cavity (Figures $1 A$ and $1 B$ ). Follow-up CT scans obtained 1 year later showed that the nodule was mobile, and had migrated laterally (Figures $1 \mathrm{C}$ and 1D). That finding was considered to be diagnostic of thoracolithiasis.

Thoracolithiasis is a rare benign condition characterized by the presence of one or more mobile free bodies, with or without calcification, in the pleural cavity. Thoracolithiasis is rarely symptomatic, and most cases are diagnosed on the basis of an incidental finding on an X-ray, on a CT scan, during surgery, or at autopsy. Mobility of the body (nodule), as demonstrated by sequential imaging studies, is the most characteristic finding. Although most such nodules are found to be mobile during follow-up, some are immobile and difficult to diagnose. Thoracolithiasis does not require any specific treatment, especially not surgical resection. ${ }^{(1-3)}$ For patients with mobile pleural calcified nodules, clinicians and radiologists should recommend clinical observation, because nodule removal might not be necessary for diagnosis.

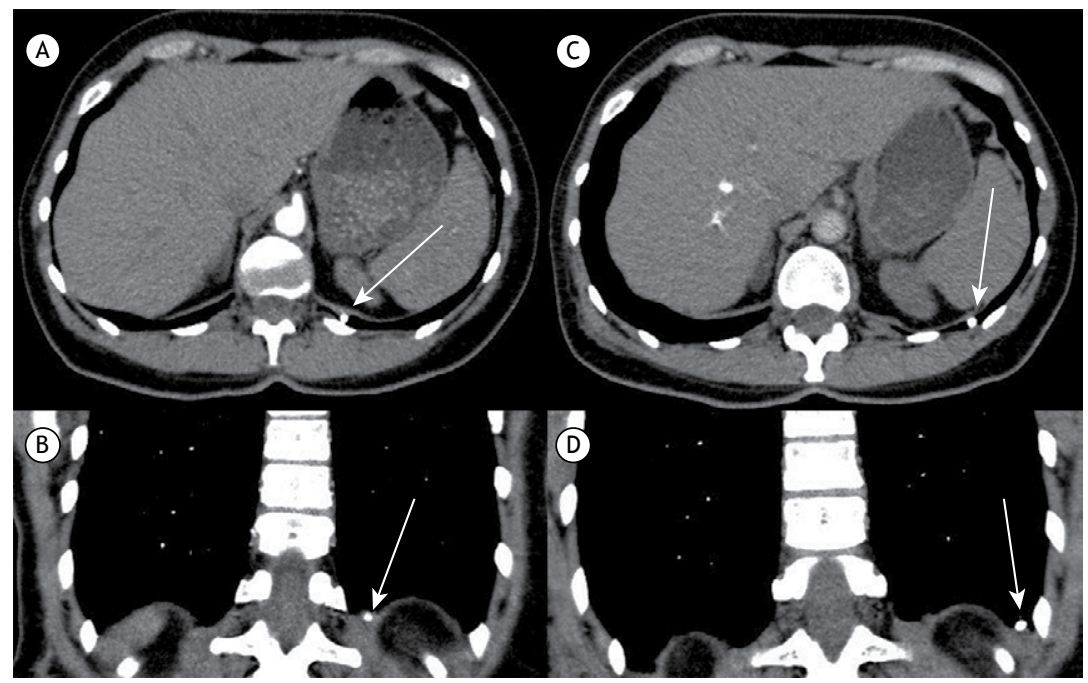

Figure 1. Axial and coronal chest CT scans ( $A$ and B respectively), with a mediastinal window setting, showing an 8-mm calcified nodule located medial to the posterior costophrenic angle. Follow-up chest CT scans acquired in the same planes ( $C$ and $D$, respectively), showing that the calcified nodule had migrated laterally.

\section{REFERENCES}

1. Peungjesada S, Gupta $P$, Mottershaw AM. Thoracolithiasis: a case report. Clin Imaging. 2012;36(3):228-30. https://doi.org/10.1016/j. clinimag.2011.08.023

2. Kim Y, Shim SS, Chun EM, Won TH, Park S. A Pleural Loose Body Mimicking a Pleural Tumor: A Case Report. Korean J Radiol.
2015;16(5):1163-5. https://doi.org/10.3348/kjr.2015.16.5.1163

3. Kinoshita F, Saida Y, Okajima Y, Honda S, Sato T, Hayashibe A, et al. Thoracolithiasis: 11 cases with a calcified intrapleural loose body. J Thorac Imaging. 2010;25(1):64-7. https://doi.org/10.1097/ RTI.0b013e3181a4ba03 